\title{
A Escola Renovada e a Família Desqualificada:do Discurso Histórico-Sociológico ao Psicologismo na Educação*
}

\section{Marcus Vinicius da Cunha}

Universidade Estadual Paulista "Júlio de Mesquita Filho" (Unesp)/ Campus de Araraquara

Analisa o discurso educacional renovador veiculado no Brasil, entre 1944 e 1960, com vistas a discutir os referenciais utilizados para compreender as relações entre escola e família.

Em outra ocasião, quando tivemos a oportunidade de analisar o desenvolvimento do ideário educacional renovador no Brasil entre 1930 e 1960, pudemos concluir que o período que se estende do final da II Guerra ao término dos anos 50 representou um momento de consolidação dos ideais escolanovistas. Com base em práticas e conceitos originários das ciências sociais e com o apoio de técnicas e saberes oriundos do terreno da Psicologia, os defensores da educação renovada enfatizaram o caráter socializador da escola. A renovação educacional visava a atender, em primeiro plano, às exigências da ordem social, o que implicava tomar os indivíduos em sua particularidade psicológica para colocá-los em sintonia com a modernização do país e com os desígnios ditados pelo progresso do mundo ocidental (cf. Cunha, 1995).

Tomaremos agora as mesmas fontes e o mesmo período já analisado. Serão vistas exclusivamente as matérias publicadas pela

*A pesquisa que deu origem ao presente trabalho toi realizada com o auxílio do CNPq. 
Revista Brasileira de Estudos Pedagógicos, do Instituto Nacional de Estudos e Pesquisas Educacionais (Inep), entre seu primeiro número, de 1944, e 1960.' Trata-se, evidentemente, de um "recorte" do período de 1930 a 1960, do qual oportunamente procuraremos dar conta, mediante a análise de outros periódicos, de aspectos diferentes dos aqui abordados.

Tentaremos verificar como eram compreendidas as relações entre a organização da família e a instituição escolar, isto é, o modo como se articulava o discurso renovador em vista do conflito entre as finalidades socializadoras da escola e a educação doméstica; mais exatamente, buscaremos esclarecer quais eram os referenciais empregados na argumentação dos educadores, que tinham, de um lado, as necessidades de um país em franca modernização e, de outro, as diversas possibilidades de educação familiar, nem sempre em sintonia com os ideais da escola. ${ }^{2}$

\section{A escola substitui a família, como prova a história}

Ao situar o papel da escola no quadro das transformações historicamente sofridas pela sociedade e, em particular, pela família, Lourenço Filho (1944, p.221) partia do princípio de que educação havia assumido "um cunho nitidamente social", razão pela qual o Estado tomava para si a incumbência de educar, considerando-a "uma necessidade de organização e de direção da vida coletiva". Mais ainda, as instituições públicas de ensino haviam deixado de ser meros locais de instrução para se tornarem coordenadoras das influências exercidas por outros setores da sociedade, como a família, a Igreja e as corporações profissionais.

\footnotetext{
${ }^{1}$ Tomar o ano de 1960 como limite justifica-se pelos critérios estabelecidos para o projeto de pesquisa em que este artigo se localiza, o que não poderá ser desenvolvido aqui.

${ }^{2}$ Os educadores estrangeiros receberão o mesmo tratamento que os nacionais, pois a pesquisa destinou-se a compreender o discurso veiculado nos meios educacionais e não especificamente entre os autores brasileiros.
} 
A elucidar o tema em estudo, Lourenço Filho (1944, p.222) se detinha na origem das instituições escolares, surgidas "para sistematizar um aspecto da educação", "a transmissão de técnicas e de informações". Essa função teria passado à escola devido a necessidades do agrupamento social, haja vista que o lar, a Igreja, a comunidade, enfim, já não podiam desempenhá-la "com a mesma economia e segurança de outros tempos". Com o decorrer dos séculos, a escola foi abrangendo um número cada vez maior de tarefas: inicialmente assumiu a preparação profissional; na Renascença lutou "contra o monopólio da sabedoria"; com os movimentos da Reforma e da Contra-Reforma, defendeu e propagou a fé; na Revolução Francesa tornou-se centro de "formação da cidadania".

Recentemente, desde o final do século XIX, à medida que incorporou o desenvolvimento dos conhecimentos científicos, particularmente no que tange à compreensão da infância e da adolescência, a escola tornou-se "um órgão capaz de funções mais completas", assumidas na esteira do "enfraquecimento da ação educativa de outras instituições sociais", dentre as quais família (Lourenço Filho, 1944, p.222). Ao longo desse tempo, a escola certamente foi sendo colocada como substituta de diversos setores tradicionalmente encarregados de suas funções próprias. Após tornar-se formadora do profissional e do cidadão, transmissora de conhecimentos que antes integravam a experiência do homem comum no terreno da religião e da política, a escola completou seu ciclo dominando os saberes que ainda sobreviviam como monopólio da família: o conhecimento dos próprios filhos, crianças e adolescentes, cujo controle o círculo familiar se orgulhava de possuir.

A educação das gerações mais novas definitivamente deixara de ser uma questão a ser resolvida no domínio privado da família para tornar-se objeto de toda a coletividade. J. Roberto Moreira (1957, p.64) considerava que determinar as funções sociais da escola era uma questão que dependia "muito mais da própria estrutura da sociedade" em que ela se localizava do que de quaisquer considerações ideológicas. O conteúdo da educação ministrada pela instituição de ensino somente seria compreendido mediante "o conhecimento das exigências que a sociedade, na sua organização, faz à escola". 
Com o intuito de exemplificar e tornar mais presente esse pressuposto, Moreira ( 1957, p.65) apresentava a cidade do Rio de Janeiro nos anos 50, onde ocorriam mudanças estruturais capazes de destruir valores tradicionalmente estabelecidos e enfraquecer instituições outrora importantes. Em consequiência desse processo, verificava-se a "quebra do poder educativo da família", resultado de sua própria desorganização no interior da acelerada mudança social enfrentada pela cidade. Concomitantemente, a escola vinha sendo chamada a assumir atribuições que antes pertenciam à família tradicional.

Esse mesmo tema era desenvolvido por Anísio Teixeira (1956, p.3), que procurava estabelecer a ligação indissolúvel entre educação e democracia. Seu "postulado fundamental" era a possibilidade de todos os homens serem "suficientemente educáveis" para "partilharem como iguais" da vida em sociedade. A "escola democrática ou para todos", portanto, teria que ser norteada por uma finalidade maior ditada pelas exigências desse regime de vida, a democracia, e fornecer uma "educação comum" a seus membros, a educação "que antes a vida espontaneamente oferecia" por intermédio da família, da classe e da "participação na vida social" (Teixeira, 1956, p.9).

A família, segundo Anísio Teixeira, já não se mostrava capaz de ministrar os ensinamentos que constituem a base dos valores e que sustentam o desempenho do indivíduo na sociedade. A complexidade das relações no mundo moderno impedia que a família e a classe permanecessem como "instituições seguras e incontrastáveis" como teriam sido no passado. Mas, acrescentava o autor, mesmo que tais instituições ainda hoje estivessem seguras de seus papéis, a escola teria a seu encargo uma tarefa impossível de ser cumprida pelo grupo familiar. A "escola comum e democrática" possui o intuito de ser o ambiente apropriado para que o educando faça a "revisão e integração de suas experiências". Desse modo, torna-se "participante inteligente e ajustado de uma sociedade de todos e para todos, em que o respeito e o interesse pelos outros se estendam além das estratificações sociais e de grupo e se impregnem do espírito de que, antes de membro da família, do grupo ou da classe, o indivíduo é membro de sua comunidade, do seu país e de toda a humanidade" (Teixeira, 1956, p.9). 
Anísio Teixeira destacava, assim, a constituição do indivíduo típico das sociedades historicamente mais desenvolvidas, em que a socialização da criança tinha em vista a construção da cidadania. Ao invés da inculcação de valores voltados à satisfação de poderes locais ou particulares - como faz a família - ,a civilização moderna exigia um modelo de homem que possuísse a visão clara de seus direitos e obrigações diante da Nação.

Anísio Teixeira preconizava uma "escola de vida, em que as matérias fossem constituídas "por experiências e atividades da própria vida", objetos de constante reflexão e reformulação; uma escola em que a meta fosse integrar a experiência individual de cada um à dos demais, de maneira a destruir "os isolamentos artificiais e as prevenções segregadoras" com o intuito de estabelecer "uma verdadeira fraternidade humana" (Teixeira, 1956, p.9).

A "escola progressiva", quando instalada, não faria mais do que recuperar "as boas condições educativas" que fizeram parte das "instituições naturais" de educação: a família, a oficina, o escritório de trabalho, o clube, a igreja..., onde a transmissão do conhecimento se dava em sintonia com os interesses e necessidades do educando e não por imposição da autoridade, onde se participava em atividades significativas para o indivíduo e para a coletividade (Teixeira, 1956, p.13).

A escola almejada por Anísio Teixeira cumpriria os desígnios que tradicionalmente foram da alçada de outras instituições sociais "naturais", dentre elas a família, proposição que vimos há pouco esboçada por J. R. Moreira e por Lourenço Filho. A educação formal, inserida numa sociedade democrática, devia atender às exigências de uma ordem social igualitária, empenhando-se para desenvolver determinados saberes e valores, tarefa que outros grupos sociais já não podiam efetivar.

Em outro escrito, Teixeira (1957, p.7) se detinha na análise dos efeitos da mudança sociocultural e destacava, mais detalhadamente, a possibilidade de desestruturação dos valores que sustentavam a democracia. O funcionamento das sociedades democráticas - sua "ordem" e sua "estabilidade" - era visto como sendo assegurado por "critérios conscientes de valor e hierarquia" tradicionalmente incutidos 
pela família e pela classe social. Aliás, Anísio Teixeira dizia que o agente responsável por essa "lenta impregnação" de valores era, "em rigor a classe, pois a família é sempre um aspecto da classe". A escola também poderia ser incluída entre os promotores desse processo estabilizador, desde que fosse uma instituição capaz de se apresentar sob a "forma de vida em comum, com atividades de participação e de integração".

Tais agentes socializadores, a classe social, por excelência, e a família, vivendo em um momento de intensa transformação do mundo, já não conseguiam dar conta da tarefa que lhes cabia, qual seja, "a transmissão pacífica dos seus padrões"; deixavam, assim, de "operar como força estabilizadora suficiente".

Fica, portanto, a escola. Se ela não se fizer a transmissora de padrões de hábitos, atitudes, práticas e modos de sentir e julgar, as forças liberadas pelo progresso material lançarão os indivíduos a uma corrida de ascensão social, tanto mais desordenada e caótica, quanto menos preparados tiverem ficado para tais promoções, situação que não é afinal senão a que vimos, presentemente, registrando no país (Teixeira, 1957, p.7).

Seguindo o raciocínio de Anísio Teixeira, o risco que se corre, nos períodos em que a sociedade tende a viabilizar aspirações de mobilidade social, é o da desarrumação da ordem harmônica reinante nas democracias. O autor entendia que a escola deveria assumir, responsavelmente, seu papel de única instituição socializadora capaz de salvar a estabilidade democrática, visto que esta se encontrava ameaçada pelo progresso social, gerador de desenfreada corrida em busca de promoção na hierarquia sem o suporte do tradicional agente refreador desta mesma corrida, a família, "aspecto da classe".

\section{A intervenção sociológica}

Sólon Kimball (1960, p.24), interessado em buscar soluções para o sistema educacional brasileiro, dizia: 
Aqui já é preciso compreender a cultura do homem comum, suas formas características de agrupamento social, procurando depois construir um programa educacional capaz de ser aceito e compreendido por aqueles a quem se destina. Neste caso, não é possível separar o programa escolar do sistema familiar, dos princípios institucionais, ou deixar de considerar o lugar ocupado pelo homem comum brasileiro na sociedade, seja ela urbana ou rural.

A questão das relações entre a escola e a família assumia, então, formas claras e inconfundíveis: tratava-se de um "problema sociológico". Como tal, obrigava a escola a manter-se atenta às peculiaridades sociais do meio ambiente do "homem comum" e a adequar-se a elas. Esse postulado colocava a escola frente a frente com a cultura específica de determinados agrupamentos que se mantinham alheios às "tradições de cultura básica", como era o caso das "classes menos favorecidas", que davam pouca ou nenhuma atenção à educação formal, o que revelava "inércia", "indiferença" e até mesmo "hostilidade" de certas famílias diante da instituição de ensino (Kimball, 1960, p.24).

Cabia ao educador ir além do conhecimento estritamente pedagógico; era sua tarefa procurar auxílio nos conhecimentos sociológicos para melhor compreender sua clientela, para desenvolver um trabalho que atraísse os pais para o círculo escolar. Projetos de orientação profissional dos educandos, por exemplo, poderiam ser postos em prática, uma vez que parecia haver "deficiência nessa orientação dentro do lar"; a pesquisa sociológica que levasse à compreensão das atitudes e expectativas dos pais seria de fundamental importância para subsidiar trabalhos dessa natureza ${ }^{3}$ (Kimball, 1960, p.25).

Kimball também sugeria "interessar os pais nos programas de manutenção e de melhoramento da escola", ações que os levassem a empregar seu tempo e seu dinheiro em benefício da instituição. Esta medida seria útil para "modificar o ambiente psicológico" reinante, em que a escola era vista apenas como encargo do poder público sem o necessário comprometimento do cidadão comum (Kimball, 1960, p.26).

${ }^{3}$ A respeito do tema, ver o artigo do National Vocational Guidance Association (1945). 
As considerações de Sólon Kimball permitiam deslocar a problemática das relações entre escola e família do âmbito da análise histórica para o terreno das ações sociologicamente dirigidas. $\mathrm{O}$ núcleo familiar, bem como a escola e a comunidade circundante tornavam-se objetos de estudo científico com vistas à aquisição de um conhecimento diretamente voltado para a intervenção na realidade.'

$\mathrm{O}$ valor dos conhecimentos sociológicos na prática pedagógica da escola renovada era enfatizado por Roger Bastide (1948, p.30), que se preocupava em ressaltar os fins sociais da educação, lembrando que "a sociedade não é somente uma livre cooperação de espíritos e de vontades" mas é também formada por "imposições coletivas, exteriores e superiores ao indivíduo, às quais ele deve subordinar-se". Caso a escola insistisse em revelar ao educando desejos e necessidades que "nem sua família nem sua comunidade tinham antes provocado", a educação estaria criando falsas expectativas na criança, uma vez que o seu ambiente, com freqüência, se interpõe a tal liberdade.

O raciocínio desse autor colocava a família, portanto, como um dique de contenção das ilusões do indivíduo; sendo uma instituição socializadora, representante das imposições sociais, portanto, cabia-lhe delimitar o alicerce psíquico sobre o qual se constituem as pretensões de trânsito do indivíduo na sociedade. Este teria sido o papel político da família tradicional que, como "aspecto da classe" - na linguagem de Anísio Teixeira, visto há pouco -, trabalhara em benefício da estabilidade da ordem social.

Mas a nova escola, imbuída dos saberes que traduzem os segredos da alma humana, possuía condições para abrir os horizontes da pessoa, despertar vontades novas, alargar suas esperanças, enfim, criar

\footnotetext{
* Essa idéia enquadrava-se quer no parecer quer no espírito do trabalho proposto por Anísio Teixeira para o Inep. Quando de sua posse como diretor do Instituto, enfatizou a necessidade de estudos empíricos que revelassem a real situação do ensino no país (cf. Teixeira, 1952). Uma pesquisa de Thaïes de Azevedo (1954) mostra que a temática da família vinha sendo abordada sob essa perspectiva, mas, ao que tudo indica, foi com os Centros de Pesquisas Educacionais, criados pelo Inep anos mais tarde, que essa linha de trabalho foi enfatizada.
} 
inédito alento psicológico para a crença na mobilidade social. O que encontramos em Bastide é a crítica a um tipo de educação que tinha potencialidade para revelar a liberdade interior impossível de ser concretizada, do que resultaria o indivíduo desadaptado e, conseqüentemente, marginalizado.

Para ser a "força estabilizadora" da sociedade - lembrando outra expressão de Anísio Teixeira - a escola deveria empregar menos os conhecimentos revelados pela Psicologia e mais as lições da Sociologia. Não para impor as obrigações do meio social "acima do progresso da pessoa humana" ou para tornar a educação um instrumento cego de adaptação do indivíduo aos desígnios da sociedade, o que significaria "rotina, conservantismo e estagnação", segundo Bastide (1948, p.31).

A Sociologia seria útil ao educador para que este reconhecesse que o "determinismo social" é um fato, que "as coisas não se podem modificar por um golpe de varinha de condão" e que "é preciso harmonizar estreitamente o aperfeiçoamento dos valores individuais com o dos valores coletivos". Só o conhecimento das "leis sociológicas" poderia levar o educador a realizar um trabalho regrado de mudança social; os saberes sociológicos exerceriam influência sobre a comunidade, oferecendo-lhe "novos valores" que seriam transmitidos aos "jovens espíritos". Estes, à medida que o meio social fosse paulatinamente abrindo possibilidades até então insuspeitadas, poderiam desabrochar "para os desejos e necessidades outrora desconhecidos".

O pensamento de Roger Bastide colocava a necessidade de a escola trabalhar a vida psíquica do indivíduo em sintonia com o desenvolvimento das instituições sociais. A liberdade individual só poderia existir na medida e no ritmo em que a sociedade fosse criando espaço para tanto. Para o autor, os educadores, norteados pelos saberes da Sociologia, seriam profissionais capazes de captar o movimento da cultura, influir sobre ele e adequar estratégias pedagógicas para o educando. Em nenhum momento o aluno e sua família seriam vistos 
como entes psicológicos puros, como espíritos e instituições passíveis de uma análise que extrapolasse o crivo sociológico ou que se mantivesse aquém deste. A família em si, bem como os próprios indivíduos que a compõem, não era mais do que um agrupamento submetido a determinações sociais do momento histórico em que se localizava.

Todos os autores até aqui tratados, respeitando-se as nuances de cada abordagem, privilegiavam os conhecimentos das ciências sociais e organizavam seus discursos sobre o tema da família a partir de uma matriz histórico-sociológica de pensamento. Dentre eles, havia até mesmo quem elevasse a importância da família, de tal modo que chegava a admitir que a escola pudesse limitar-se à tarefa de instruir, no sentido estrito da palavra. Almeida Júnior ( 1946, p.89) acreditava que à redução do número de membros do agrupamento familiar correspondia um aumento em sua capacidade adaptativa, a exemplo do que ocorrera, afirmava o autor, no âmbito biológico quanto à diminuição das dimensões físicas dos animais inferiores.

O autor sustentava a crença na sobrevivência da família, instituição que já havia abolido a "tirania do chefe" em proveito de um "regime democrático" em que mulher e filhos "participam do governo do lar". A família vinha resistindo às transformações sociais, mesmo àquelas que deram margem a procedimentos educacionais coletivizados, tão danosos à formação psicológica das crianças, como era o caso da União Soviética (Almeida Júnior, 1946, p.90-91).

Não havia evidências de que a eficácia da família pudesse ser superada por qualquer outro sistema educacional, particularmente quanto a "lançar as primeiras e mais profundas raízes da formação moral e afetiva da criança". A escola devia limitar-se a "continuar a educação", atendose em especial à pura e simples instrução (Almeida Júnior, 1946, p.91). Se se observasse as características dos lares norte-americanos, poderse-ia extrair dali algumas lições para criar ambientes mais higiênicos e estimulantes da saúde, o que certamente exerceria grande influência sobre a educação dos espíritos infantis. 
Em tese, correto. Porém, em oposição à "máquina de morar" existente nos países do Norte, tínhamos "os cortiços e as casas operárias de São Paulo", "as moradias pobres do Rio de Janeiro" e "os mocambos do Recife", habitações "em que vivem - ou melhor, em que vegetam milhares, senão milhões de criaturas humanas, desde crianças recémnascidas, até velhos em decrepitude" (Almeida Júnior, 1946, p.87).

No raciocínio de Almeida Júnior (1946, p.87-88), podia-se perceber a clara distinção entre dois tipos de família. De um lado, aquelas que haviam superado os moldes antigos de organização patriarcal, que podiam almejar alçar-se ao modelo dos Estados Unidos da América, que tinham condições adequadas para educar os filhos; para estas, podiase aplicar a tese da escola meramente instrutora, da instituição que simplesmente continuava o que os pais já tinham iniciado no campo dos valores e do comportamento. Quanto às demais famílias, era tão grande a "extensão do mal" que para "anular os malefícios das péssimas condições em que essa gente vive", para transformar esses ambientes tão danosos às futuras gerações, não haveria educação higiênica que bastasse. Seria preciso grande mobilização das forças vivas da sociedade' "até que apareça alguém que consiga resolver este gravíssimo problema".

Embora não esclarecesse a quem caberia apresentar tais soluções, percebe-se que Almeida Júnior colocava a organização do ambiente familiar das camadas pobres sob a alçada de forças políticas e sociais. A ação direta sobre as famílias, na forma de campanhas higiênicas ou outras que a escola pudesse viabilizar, não atingiria o objetivo de alterar modos de vida já cristalizados no meio doméstico das famílias pobres. Os padrões indesejáveis de comportamento eram vistos como consequiências de processos a serem abolidos por ações coletivas no âmbito social; não eram causados por qualquer entidade instalada no psiquismo das pessoas pobres ou, para não irmos tão longe, na consciência

${ }^{5} \mathrm{O}$ autor conclamava o Idort. para o qual. na ocasião, realizava a conferência, a cumprir esse papel mobilizador. 
que estas pessoas tinham sobre higiene, estruturação familiar ou educação dos filhos.

Não seria exagerado dizer que em todos esses autores o cerne dos problemas da sociedade, e da escola em particular, localizava-se no modo como as instituições sociais haviam se desenvolvido, o que acabara por decretar a insuficiência da família enquanto órgão educador. A causa dos males da família não se encontrava nela mesma - vale dizer, nos indivíduos componentes do grupo doméstico -, posto que a família representava tão somente um resultado do ambiente social tramado no interior de um processo histórico e de uma conjuntura sociologicamente explicável.

\section{A intimidade doméstica, objeto da Psicologia}

Outros educadores, mesmo apoiando-se, de modo semelhante aos precedentes, num certo princípio de determinismo ambiental, iam além da matriz histórico-sociológica de pensamento; seu intuito era buscar aprofundamento nas peculiaridades das relações domésticas. Era o caso de Margareth Hall (1946, p.258). que partia de uma análise sociológica da educação e chegava ao outro pólo do universo escola-familia. Para a autora, a instituição da gratuidade e da universalidade do ensino criara o fato de a escola ter que lidar com uma massa heterogênea de alunos e determinara que o conceito de educação passasse a abranger responsabilidades ligadas à formação do caráter e ao desenvolvimento emocional das crianças, tópicos tão importantes quanto as tradicionais atribuições da escola, circunscritas ao terreno intelectual. Diante das diferenças entre os educandos e dos problemas de adaptação destes à situação escolar, já estava em uso a técnica do "diagnóstico educativo" com vistas a identificar as causas dos problemas da clientela.

Tais causas, segundo Hall (1946, p.260), podiam ser de variada natureza, envolvendo desde fatores físicos, intelectuais e emocionais até 
razões de ordem ambiental, como o programa de ensino, o próprio meio escolar, as "condições domésticas" e a "atitude dos pais". Referindo-se a um estudo de caso, a autora dizia:

Da entrevista com os pais o psicólogo escolar pode obter muitos dados valiosos a respeito dos seguintes fatores: baixo nível cultural do lar; pobre vocabulário dos membros da família; falta de interesse pela Leitura e por toda atividade de ordem cultural ou intelectual; antagonismo para com as coisas do intelecto; falta de cooperação entre o lar e a escola, e estreiteza de interesses (Hall, 1946, p.266).

A abordagem da autora norte-americana diferia das anteriormente vistas porque visava a detectar os problemas da organização familiar no âmbito das particularidades de cada família. Saíam de cena o historiador e o sociólogo para darem lugar ao psicólogo escolar que, munido de seus instrumentos de investigação do psiquismo, capacitavase a adentrar na intimidade das relações entre pais e filhos e a aquilatar suas deficiências no que tivessem de prejudicial ao bom desempenho escolar das crianças. Tornava-se possível sugerir a correção desses entraves; por meio de entrevista com os pais podia-se tentar modificar seus conceitos sobre a educação dos filhos, que "precisam de estímulo, tolerância, simpatia e apoio moral em vez de repreensões, críticas e castigos" (Hall, 1946,p.268).

As idéias de Margareth Hall destinavam-se a substituir determinados procedimentos de educação dos filhos, tradicionalmente adotados no seio da família, por técnicas cientificamente aprovadas. A suposição básica desse tipo de argumento era que a personalidade da criança dependia fundamentalmente do tipo de ação educativa dos pais, a qual poderia gerar crianças "anormais de caráter" (Ciulla, 1947), enquadráveis em extensas classificações médico-psiquiátricas. Fatores ambientais, como a "situação social dos pais, sua moral, seus meios pecuniários" (p. 191), eram vistos como geradores de "indivíduos que 
não se integrarão na sociedade", dado o comportamento associai resultante do mau desenvolvimento de sua afetividade na infancia (p. 189).

Requisitava-se então uma Psicologia normalizadora. Se no tocante à saúde física os pais já adotavam a visita profilática ao pediatra, o mesmo deveria ocorrer quanto às condições de ajustamento psíquico das crianças, pensava Maurício de Medeiros (1949, p.66). O autor, que chegou a organizar uma lista dos dez mandamentos para a boa educação, preconizava a importância da "escola maternal" para ensinar a vida em grupos e para estimular o desenvolvimento intelectual dos educandos. ${ }^{6}$

Esses autores, ao fazerem referência à individualidade da vida psíquica da criança, tratavam o assunto a partir de uma perspectiva ambientalista, uma vez que o desenvolvimento emocional e afetivo era visto como estando na dependência direta dos meios de subsistência da família. Nessa linha de análise, quanto mais degradadas as condições de organização do grupo familiar, maiores os desajustes psicológicos da criança, como dizia Medeiros (1947, p.408):

O baixo nivel econômico se, por um lado, favorece a luta pela vida precocemente, multiplicando as formas de reação em padrões superiores aos da idade da criança, por outro lado, desenvolve os vícios sexuais, rebaixa a linguagem, avilta as atitudes morais pela promiscuidade com adultos da mesma categoria.

Nessa corrente de pensamento também havia uma linha de diferenciação a separar, numa extremidade, famílias de poder aquisitivo superior e, em outra, famílias pobres - a exemplo do que vimos no discurso de matriz sociológica. Sua especificidade era conferida, então, pelo fato de mencionar a constituição do psiquismo infantil, que dependia do "nível econômico". É relevante observar que, nessa perspectiva, a

${ }^{6}$ Em Medeiros (1951) tinha-se a transcrição de uma conferência em que o autor procurava ensinar aos pais como entender o mundo imaginário das crianças 
admissão da existência de entidades psíquicas interiores não invalidava a tese do meio social com o fator determinante; aliás, eram justamente os diferentes meios sociais que produziam diferentes tipos de personalidade.

Tal distinção podia ser claramente vista também em Ofélia Boisson Cardoso (1945, p.177-178), que localizava o agravamento dos problemas infantis no ingresso da criança na escola primária, ocasião em que as exigências da aprendizagem sistemática a colocavam sob um clima sensivelmente diferente daquele a que estivera habituada no jardim de infância e no seio da família. Em acréscimo às dificuldades colocadas por um tipo mais intenso de socialização, como ocorre no ensino primário, surgiam os conflitos motivados pela diferença entre os tratamentos doméstico e escolar. De um lugar onde "é ela mimada, suas vontades são logo atendidas", onde "é um pequenino tirano, cujos desejos são leis", a criança é colocada num ambiente em que "seus desejos são muitas vezes contrariados", em que existem outros indivíduos "no mesmo pé de igualdade".

Como podemos perceber, Ofélia Cardoso analisava crianças de classe média ou alta, que recebiam tratamento privilegiado em seus lares. Tais crianças tinham "problemas de perturbação de caráter" cujas causas se encontravam em seu passado, nos comprometimentos afetivos gerados pelo zelo excessivo dos pais; no futuro, poderiam tornar-se "revoltados", adolescentes de classe média desajustados por lhes terem usurpado a confortável situação de pequenos reis do lar. Para os casos em questão, a autora apresentava uma série de sugestões para uma abordagem clínica das crianças-problema, sem mencionar qualquer estratégia de ação sobre as famílias.

Ofélia Cardoso (1949, p.81), ao tratar o assunto à luz dos conhecimentos sociológicos, reconhecia a relevância dos fatores sociais na formação da personalidade, bem como a importância da 
hereditariedade. Não deseja tornar-se adepta dos "ambientalistas extremados" que viam "o resultado da aprendizagem como conseqüência direta do ambiente, atribuindo-lhe toda a responsabilidade", mas não havia como não perceber que, ao lado de outros componentes, o ambiente tinha seu peso.

Bastava observar a "sórdida promiscuidade" em que se apinhavam pais e filhos nas moradias dos bairros pobres:

Em casos como esses, o meio familiar, em que a criança passa a maior parte do tempo, é, em tudo, a antítese do meio escolar. O que a escola procura construir a família destrói, num momento reduz a pó. Os exemplos vivos e flagrantes insinuam-se na carne, no sangue das crianças, ditando-lhes formas amorais de reação, comportamentos anti-sociais (Cardoso, 1949, p.82).

Vivendo uma "vida sem normas, sem direção", integrando grupos de delinqüentes, "não há como controlar-se: a reação é espontânea, primitiva, quase que irracional"; a lei que prevalece é a do mais forte; a moral que se impõe rejeita princípios que não visem "à defesa do pão, à conquista de um canto para dormir". As crianças se desinteressam pelo trabalho escolar, pois tudo o que a escola lhes dita "parece falso", soa como utensílio de uso exclusivo no ambiente da sala de aula e não no cotidiano agressivo de seu bairro. Ofélia Cardoso (1949, p.83) notava que a escola se debatia diante de um problema que era, "no fundo, um problema econômico" que permanecia insolúvel. A escola sequer conseguia "falar a mesma língua da comunidade" a quem devia educar.

Com o intuito de conferir certa generalidade à influência dos condicionantes sociais, a autora retomava o tema das crianças problemáticas oriundas de "famílias de nível econômico elevado". Tornava-se então sensível a mudança no vocabulário empregado por ela, talvez para adequar-se à leveza dos conflitos presentes na família de "ótimo nível cultural", em comparação com a rudeza dos demais. 
Eram "problemas gravíssimos" tais como

...o do filho único, o da criança que se enche de ciúmes, detestando o irmãozinho recém-nascido, alvo dos cuidados maternos, a fixação do filho a sua mãe e a hostilidade para com o pai etc. Por vezes, carinhos e afagos exagerados, superproteção e indulgências fora do normal, por parte de pais, tios ou avós, determinam nas crianças o aparecimento de condições que as transformam em desajustadas, impossibilitadas de participarem ativamente do trabalho escolar (Cardoso, 1949, p.83).

Após refletir sobre ambos os tipos de famílias, a autora via por bem propor a regra geral de que a escola desenvolvesse um trabalho educativo e conclamasse os pais a participarem de seus empreendimentos.

\section{O "psiquismo profundo" e o ambiente familiar}

Como vemos, boa parte dos autores que analisavam as relações entre a escola e o grupo familiar abordava o tema fazendo referência aos problemas psicológicos passíveis de serem encontrados na família moderna. Parecia certo que os pais eram os responsáveis diretos pelos desajustamentos, anomalias, "complexos" (cf. Costa, 1948), enfim, pela formação da personalidade dos filhos e, conseqüentemente, pelo seu maior ou menor ajustamento à situação escolar (cf. Veloso, 1958).

Esses educadores mencionavam particularmente o ambiente familiar dos meios sociais pobres. Quer fosse uma abordagem genérica sobre a família, quer específica sobre a família pobre, certos discursos traziam propostas de ações diretas sobre o grupo familiar com a intenção de normalizar as atitudes adotadas no âmbito da vida privada. Sem abrir mão de considerar que o psiquismo era formado pelo ambiente, passavam a recomendar a utilização de recursos metodológicos capazes de buscar na observação e classificação dos comportamentos, presentes e passados, a razão dos desvios de personalidade. 
A recomendação de tais recursos aparecia, por vêzes, envolta em roupagens teóricas que sugeriam a necessidade de aprofundamento nos recônditos mais obscuros da alma humana. Destacando-se do raciocínio histórico-sociológico, os saberes da Psicologia, especialmente aqueles que buscavam revelar o espaço psicológico mais íntimo, ganhavam relevância. Ainda que situados num contexto em que a causa maior dos desvios psicológicos era atribuída à malignidade da ordem social, esses discursos davam tamanha ênfase ao psicológico - e, inevitavelmente, às estratégias interventoras neste terreno - que todos os demais determinantes pareciam adquirir importância reduzida.

Lúcia Marques Pinheiro (1951, p.57), então, recorria às elaboradas teorias de Karen Horney para mostrar que os conhecimentos científicos podiam ser aplicados "diretamente em educação". Considerava que os pilares do desenvolvimento emocional da personalidade eram formados no decorrer das experiências da criança junto à família e que, portanto, os educadores deveriam contribuir para a boa "formação moral, psicológica e pedagógica dos pais" (idem, p.74). Quanto menos habilitada a cuidar dos filhos, mais a família deveria recorrer aos profissionais cientificamente orientados para educar.

Para Ernesto Nelson ( 1945, p.329), o que distinguia nossa escola, em oposição à do mundo europeu, ${ }^{7}$ era que nossos processos de classificação e seleção fundamentavam-se "no reconhecimento de uma hierarquia das condições biológicas e espirituais das crianças", o que permitia abrir caminhos para a evolução da personalidade dos educandos.

Era de se estranhar, dizia o autor (Nelson, 1945, p.330), que não se tivesse dado aos pais as condições necessárias para sintonizá-los com as preocupações sustentadas pelas instituições formais de educação. A família não possuía conhecimentos que a capacitassem a conhecer "a alma e as tendências dos seus filhos":

${ }^{7} \mathrm{O}$ autor, que era argentino, nao esclarecia se sua referência era local ou se estava apresentando Uma versão da realidade do ensino no continente americano. 
Quantos meninos violentos, irascíveis ou impulsivos, quantos indisciplinados, vadios, ou cleptômanos, têm vivido sem que seus pais hajam adotado atitude inteligente diante das primeiras manifestações de seu temperamento

Além dessas crianças portadoras de dificuldades facilmente identificáveis, havia outras que, de "vida aparentemente normal", na verdade apresentavam sérias "anormalidades de caráter": "a criança mimada, o manhoso, o brigão...", todos eles futuros desadaptados sociais (Nelson, 1945, p.331). Ao discorrer sobre os "anormais do caráter", do ponto de vista de Freud, Adler e Jung, Ernesto Nelson falava do "laço inviolável" que liga a criança aos pais, especialmente o "laço psíquico" entre a mãe e o filho, que "equivale à identidade do subconsciente de um e de outro", elo "invisível e imaterial" que permite "o intercâmbio de emoções e intuições entre o subconsciente de ambos os seres" (p.334).

$\mathrm{O}$ autor defendia a necessidade de os pais conscientizarem-se de que educar os filhos não podia continuar sendo "um processo cego e rotineiro", pois "o jogo das forças que eles involuntariamente põem em movimento", se descontrolado, teria efeitos "ruinosos sobre a vida ulterior da criança". As crianças problemáticas eram vistas como geradas por atitudes erradas dos próprios pais. A delinquiência infantil, por exemplo, resultaria de forçarem as "inclinações naturais dos filhos" por causa do desejo de compensarem seus fracassos na vida; as más condutas seriam provocadas pela dissonância verificada entre o rigor disciplinar do pai e a complacência da mãe. Embora não se estendesse sobre o assunto, Nelson também listava, entre as causas das anomalias em questão, os conflitos provocados pelo não atendimento das necessidades da criança devido às "condições de vida da família" (Nelson, 1945, p.336).

Isoladamente, o professor nada poderia fazer pelos educandos com problemas de conduta; precisaria que a escola "criasse relações orgânicas com o lar", programas de "auxílio mútuo", fundamentados no 
conhecimento científico e aplicáveis na prática. Segundo Nelson, o reconhecimento de que o estudo das disfunções da criança só seria verdadeiramente revelador se feito à luz do "conhecimento pessoal dos que com ela convivem no lar" levou a escola a estabelecer um meio de contato mais próximo com a família: a "professora visitadora", função inspirada na "visitadora de higiene" cujo trabalho já era "familiar ao público de todo o mundo"8 (Nelson, 1945, p.345).

$\mathrm{O}$ recurso técnico dessa profissional era, fundamentalmente, o "estudo de casos individuais", o que lhe propiciava condições para analisar a situação e formular um diagnóstico dos problemas de conduta e de personalidade do aluno. Ela tinha em vista trabalhar não só com as dificuldades apresentadas pela criança na escola, mas também com as anomalias verificadas no ambiente doméstico. Para a consecução de seu trabalho, a professora visitadora fazia entrevistas com os envolvidos e aplicava testes psicológicos nas crianças, podendo contar, também, com avaliação de psiquiatras. Por fim, construía um quadro em que se incluíam dados a respeito do desenvolvimento do educando, de seu "nível mental", de sua "história social" e de seus "conflitos mentais" (Nelson, 945, p.347-348). Disso tudo, resultavam esforços para transformar atitudes, com o objetivo de que as condições no lar e na escola fossem dirigidas ao "bem-estar físico e moral da criança".

Maria Leite da Costa (1949, p.22), também abordava os desajustes da personalidade infantil, fazendo semelhante menção a esse universo psíquico subjetivo. Considerava que a desadaptação do indivíduo poderia provir de fatores constitucionais, de lesões orgânicas, de natureza interior", ou de "ação externa, de influência do meio, de causas familiares ou erros de educação". Assim, a autora discordava da crença de que os supostos "defeitos" estivessem "sempre na criança", orno certos educadores erroneamente afirmavam.

Nos casos em que o desenvolvimento psicológico da criança estivesse perturbado por causas provenientes "do ambiente que a cerca,

Novamente o autor não oferecia indícios de sua referência geográfica.

bras. Est. pedag., Brasília, v.77, n.186, p. 318-345, maio/ago. 1996. 
das próprias relações com os pais, com os irmãos, com o grupo familiar", o procedimento mais correto seria que o psicólogo passasse a atuar junto aos pais:

A realidade demonstra que um grande número de crianças difíceis provém de famílias em situação anormal, ou por os pais serem divorciados, ou um deles ter falecido ou abandonado o lar, ou a criança ter sido entregue aos cuidados de um parente mais ou menos afastado, ou ainda por ter tido de se habituar à presença dum padrasto ou de uma madrasta (Costa, 1949, p.22).

As famílias em situação de anormalidade deveriam ser minuciosamente observadas pelos olhos atentos do psicólogo:

Para o estabelecimento do diagnóstico psicológico, nenhum fator pode ficar esquecido ou desaproveitado. Além das provas efetuadas no gabinete de observação, o psicólogo vigia constante, embora disfarçadamente, o comportamento do indivíduo, reparando nos mínimos pormenores, na maneira como brinca, como está à mesa, como olha para os companheiros, como se veste e como dorme. Minúcias que aos olhos dos leigos passariam despercebidas podem constituir para o psicólogo a chave do diagnóstico (Costa, 1949, p.25).

A proposição de Maria Leite da Costa revelava uma primorosa estratégia de investigação da subjetividade da criança. $\mathrm{O}$ ambiente doméstico passava a ser visto como um local que permitia descobrir filigranas psíquicas não captáveis na situação fria de laboratório; transformado em objeto da sagacidade disfarçada do psicólogo, o lar tornava-se terreno apropriado para o exercício de uma "psicologia da vigilância". Maria da Costa $(1949$, p.25) atribuía a esse trabalho a capacidade de elucidar o tipo de infância vivido pela criança: se foi uma "infância miserável" ou não, se transcorreu "no seio de família sã ou num lar desorganizado", se esteve marcada pelo excesso de "mimos" ou de "maus tratos" etc. Enfim, nessa perspectiva, o elemento psicológico 
deveria ser confrontado com o social, e era dessa conjunção de fatores que adviria o diagnóstico.

Ao analisar os casos de "fugas infantis", a autora (Costa, 1945, p.416-417) oferecia uma demonstração do método preconizado, que dava conta de problemas importantes sob o aspecto psicológico, pedagógico e sociológico. O sintoma da fuga era caracterizado pelo "abandono, mais ou menos voluntário e impulsivo do domicílio familiar, da escola ou mesmo da oficina", quando o indivíduo perdia a "noção do real" e saía caminhando "apenas dominado pela idéia de mudar de lugar, sem sentir a fadiga e o desconforto". Mesmo associado ao roubo, esse quadro não podia ser confundido com a simples "vadiagem"; ao passo que este comportamento era um problema de natureza eminentemente social, sob a alçada do educador, a fuga podia ser a manifestação de "perturbações mentais graves, como a epilepsia e a demência precoce" ou, menos grave, de "reações de origem afetiva" provocadas pelo meio familiar. Nos meios familiares pobres, os condicionantes ambientais propiciavam a síndrome da fuga sucedida pelo comportamento de vadiagem.

Dos casos em estudo, ${ }^{9}$ a autora dizia:

...o inquérito às condições de vida das constelações familiares das crianças estudadas mostrou, repetidas vezes, haver perturbações graves do ambiente familiar, quer por desorganização dos seus elementos, quer em virtude de péssimas condições econômicas. Outras vezes, apurou-se pernicioso contágio com um meio moralmente mau, sobretudo no caso das crianças que habitam bairros ou freqüentam a deletéria promiscuidade dos pátios e de certas ruas (Costa, 1945, p.422).

A "desorganização familiar" era vista por Maria da Costa como um dos principais fatores responsáveis pelo "comportamento anômalo

' A pesquisa da autora referia-se a estudos feitos no Instituto Costa Ferreira, de Lisboa, Portugal 
da criança", em se tratando de crianças dotadas de "inteligência normal"; "seu psiquismo aparece perturbado por reações afetivas em face da desordem e da aridez do ambiente" (Costa, 1945, p.426). Os educadores tinham importante papel a cumprir junto a crianças que, por razões de debilidade mental, por anormalidades hereditárias ou ainda ameaçadas "pelo abandono moral e material", estivessem propensas a "cair na vadiagem, no vício, no crime". Cabia-lhes readaptar esses educandos e transformá-los "em indivíduos úteis para a sociedade". Mais do que oferecer ao grupo social um indivíduo refeito, a contribuição dos educadores teria o intuito de livrar a sociedade de um "elemento mau, pernicioso, indesejável" (Costa, 1945, p.430-431).

Podemos observar nesse tipo de discurso que a origem dos problemas se situava no terreno psicológico, sobre o qual deveriam ser articuladas as estratégias de intervenção. Mesmo quando considerada como resultado das determinações do ambiente social - a exemplo do que encontramos no discurso de matriz histórico-sociológica- ,a família tornava-se agora a responsável imediata pelos desajustes psicológicos de seus membros, em especial das crianças. Se no contexto do pensamento histórico-sociológico ficava esmaecida a trama psicológica ao serem ressaltados os fatores sociais, agora vemos alçar-se o espaço psicológico interno dos pais ao primeiro plano.

\section{Algumas conclusões}

Sob qualquer uma das perspectivas adotadas, uma conclusão parecia inquestionável para o pensamento educacional renovador: as famílias haviam se tornado incapacitadas para a tarefa de educar os próprios filhos, devendo delegar à escola esta responsabilidade. Do ponto de vista histórico, um processo inexorável havia concentrado os saberes no terreno da instituição escolar e nas mãos de seus profissionais, 
vitimando as famílias, que se tornaram desprovidas de qualidades para educar. Pelo enfoque sociológico, as leis de organização da sociedade moderna determinavam a impossibilidade de o indivíduo ficar à mercê das tradições particularistas da família, posto que a ordem social continha exigências acima deste plano.

De um ponto de vista mais geral, o discurso renovador enquadrava-se no interior de uma perspectiva ambientalista em que cabia requisitar a ação normalizadora de variados órgãos da sociedade e o conhecimento de diversos terrenos científicos, com especial destaque para as ciências sociais. No caso especial das famílias pobres, devia-se estabelecer uma estratégia de intervenção capaz de salvá-las das consequiências malignas do ambiente degenerado em que viviam.

A meta da renovação educacional era regenerar a sociedade; o indivíduo era visto apenas como um meio para a efetivação deste desígnio; a atuação dos educadores sobre os educandos deveria visar ao desenvolvimento de traços subjetivos adequados à nova ordem social. Foram justamente essas características que tornaram possível caracterizarmos o pensamento educacional renovador como imbuído de ideais socializadores, avessos ao psicologismo que encaminharia a escola na direção de enxergar o indivíduo isolado dos condicionantes sociais (cf. Cunha, 1995).

O que vemos agora é que o discurso dos educadores, ao vislumbrar os integrantes da família como indivíduos dotados de um espaço psicológico degradado sobre o qual atuar, tenderam a obscurecer os princípios socializadores da Escola Nova, abrindo caminho, assim, para uma interpretação psicologista do ambiente familiar. Ao entender que o psiquismo era o local onde se firmavam os alicerces da sociedade, o pensamento educacional renovador deixou-se permear pelos conceitos de uma Psicologia normalizadora da personalidade, invasora da intimidade doméstica e, mais ainda, do terreno da subjetividade.

Nesses novos componentes do discurso escolanovista pode estar a origem de sugestões para que o trabalho docente passasse a atuar sobre o educando enquanto ser psicológico apartado do social. Considerando 
que nenhum autor é capaz de limitar o tipo de interpretação que sobrevirá às suas propostas, nada impedia que os leitores e divulgadores das idéias difundidas naquela época as assimilassem do modo que lhes fosse mais conveniente. Embora aqui não o tenhamos visto explicitamente formulado, nas entrelinhas do discurso escolanovista já repousava o esquecimento das questões sociais e políticas que envolvem a compreensão da família, do educando e da escola.

Referências bibliográficas

ALMEIDA JÚNIOR, Antônio. A educação higiênica no lar. Revista Brasileira de Estudos Pedagógicos, Rio de Janeiro, v.7, n.19, p.7592, jan. 1946.

AZEVEDO, Thaïes de. As famílias dos alunos de uma escola primária. Revista Brasileira de Estudos Pedagógicos, Rio de Janeiro, v.22, n.56,p.116-143, out./dez. 1954.

BASTIDE, Roger. A educação dos educadores. Revista Brasileira de Estudos Pedagógicos, Rio de Janeiro, v.12, n.33, p.20-43, maio/ago. 1948.

CARDOSO, Ofélia Boisson. Alguns problemas de perturbação de caráter. Revista Brasileira de Estudos Pedagógicos, Rio de Janeiro, v.3, n.8, p. 176-184, fev. 1945.

. O problema da repetência na escola primária. Revista Brasileira de Estudos Pedagógicos, Rio de Janeiro, v. 13, n.35, p.7488,jan./abr. 1949.

CIULLA, Luiz. Menores anormais de caráter. Revista Brasileira de Estudos Pedagógicos, Rio de Janeiro, v.10, n.27, p. 187-205, mar./ abr. 1947. 
COSTA, Maria I. Leite da. Aplicação dos métodos psicopedagógicos no estudo das fugas infantis. Revista Brasileira de Estudos Pedagógicos, Rio de Janeiro, v.6, n.18, p.416-431, dez. 1945.

- Complexos infantis. Revista Brasileira de Estudos Pedagógicos, Rio de Janeiro, v.12, n.32, p.50-69, jan./abr. 1948.

. O diagnòstico psicològico nas crianças difíceis. Revista Brasileira de Estudos Pedagógicos, Rio de Janeiro, v. 13, n.35, p. 1926, jan./abr. 1949.

CUNHA, Marcus Vinicius da. A educação dos educadores: da Escola Nova à escola atual. Campinas: Mercado de Letras, 1995.

HALL, Margareth. A importância do diagnóstico educacional. Revista Brasileira de Estudos Pedagógicos, Rio de Janeiro, v.7, n.23, p.258268,jul./ago. 1946.

KIMBALL, Sólon T. Uma apreciação do ensino primário. Trad. Maria Helena Rapp. Revista Brasileira de Estudos Pedagógicos, Rio de Janeiro, v.33, n.77, p. 16-33, jan./mar. 1960.

LOURENÇO FILHO, Manuel Bergstrom. Modalidades de educação geral. Revista Brasileira de Estudos Pedagógicos, Rio de Janeiro, v.1,n.2,p.219-225, ago. 1944.

MEDEIROS, Maurício de. Aspectos da psicologia infantil. Revista Brasileira de Estudos Pedagógicos, Rio de Janeiro, v. 13, n.27, p.6578, set./dez. 1949.

. Desajustamentos infantis. Revista Brasileira de Estudos Pedagógicos, Rio de Janeiro, v.10, n.28, p.393-409, maio/jun. 1947. 
MEDEIROS, Maurício de. O mundo imaginário das crianças. Revista Brasileira de Estudos Pedagógicos, Rio de Janeiro, v.15, n.42, p.518, abr./jun. 1951.

MOREIRA, João Roberto. Funções sociais e culturais da escola. Revista Brasileira de Estudos Pedagógicos, Rio de Janeiro, v.27, n.66, p.5381, abr./jun. 1957.

NATIONAL VOCATIONAL GUIDANCE ASSOCIATION (Nova York). Princípios e práticas de orientação educacional e profissionai. Trad. Manuel Bergstrom Lourenço Filho. Revista Brasileira de Estudos Pedagógicos, Rio de Janeiro, v.5, n.13, p.21-34, jul. 1945.

NELSON, Ernesto. Necessidade do estudo da criança no lar e na escola. Revista Brasileira de Estudos Pedagógicos, Rio de Janeiro, v.5, n. 15, p.329-352, set. 1945.

PINHEIRO, Lúcia Marques. Aplicações da psicologia à educação: origem dos sentimentos de insegurança e angústia. Revista Brasileira de Estudos Pedagógicos, Rio de Janeiro, v.15, n.41, p.54-74, jan./mar. 1951.

TEIXEIRA, Anísio S. Discurso de posse do professor Anísio Teixeira no Instituto Nacional de Estudos Pedagógicos. Revista Brasileira de Estudos Pedagógicos, Rio de Janeiro, v. 17, n.46, p.69-79, abr./jun. 1952.

A escola brasileira e a estabilidade social. Revista Brasileira de Estudos Pedagógicos, Rio de Janeiro, v.28, n.67, p.329, jul./set. 1957.

. O processo democrático de educação. Revista Brasileira de Estudos Pedagógicos, Rio de Janeiro, v.25, n.62, p.3-16, abr./jun. 1956. 
VELOSO, Elisa Dias. Problemas de ajustamento à escola. Revista Brasileira de Estudos Pedagógicos, Rio de Janeiro, v.30, n.71, p. 1529, jul./set. 1958.

Recebido em 22 de julho de 1996.

Marcus Vinicius da Cunha, doutor em História e Filosofia da Educação pela Universidade de São Paulo (USP), é professor assistentedoutor junto ao Departamento de Psicologia da Educação da Faculdade de Ciências e Letras da Universidade Estadual Paulista "Júlio de Mesquita Filho" (Unesp), campus de Araraquara-SP.

This article analyses the discourse of educational renovation in Brazil, between 1944 and 1960. It discusses the concepts that were used to Understand the relationship betwen school and family.

Le but de Ia presente étude est celui d'analyser le discours éducateur rénovateur utilisé au Brésil, entre 1944 et 1960, pour reflechir sur les rapports entre la famille et l'école.

En este trabajo se analiza el discurso renovador de la educación producido en Brasil entre 1944 y 1960, discutiéndose los conceptos usados para comprender Ias relaciones establecidas entre escuela y familia. 